\title{
AVALIAÇÃO DE DIFERENTES NÍVEIS DE DESBASTE NAS PROPRIEDADES DA MADEIRA E DO CARVÃO VEGETAL DE Eucalyptus grandis x Eucalyptus urophylla
}

\author{
Aylson Costa Oliveiraㄹ, Maria Fernanda Vieira Rocha² ${ }^{2}$ Bárbara Luísa Corradi Pereira ${ }^{3}$, \\ Angélica de Cássia Oliveira Carneiro ${ }^{4}$, Ana Márcia Macedo Ladeira Carvalho ${ }^{4}$, Benedito Rocha Vital ${ }^{5}$ \\ 1Eng. Florestal, Mestrando em Ciência Florestal, UFV, Viçosa, MG, Brasil - aylsoncosta@gmail.com \\ ${ }^{2}$ Eng ${ }^{a}$. Florestal, M.Sc., UFV, Viçosa, MG, Brasil - mfvrocha@ hotmail.com \\ ${ }^{3}$ Eng $^{\text {a }}$. Florestal, Mestranda em Ciência Florestal, UFV, Viçosa, MG, Brasil - babicorradi@ gmail.com \\ ${ }^{4}$ Eng $^{\mathrm{a}}$. Florestal, Dr ${ }^{\mathrm{a}}$., Depto. de Eng. Florestal, UFV, Viçosa, MG, Brasil - cassiacarneiro1@gmail.com; ana.marcia@ufv.br \\ ${ }^{5}$ Eng. Florestal, Dr., Depto. de Eng. Florestal, UFV, Viçosa, MG, Brasil - bvital@ufv.br \\ Recebido para publicação: 05/07/2010 - Aceito para publicação: 04/10/2011
}

\begin{abstract}
Resumo
O presente trabalho teve como objetivo avaliar os efeitos de diferentes níveis de desbaste nas propriedades físicas e químicas da madeira e do carvão vegetal de híbrido de Eucalyptus urophylla W. Hill ex Maiden x Eucalyptus grandis S. T. Blake. O experimento foi instalado em um talhão de uma empresa do setor florestal, que foi dividido em quatro faixas, representando os níveis de desbaste de 0, 20, 35 e 50\% aplicados ao povoamento aos cinco anos. Foram coletadas 3 árvores de cada tratamento, 62 meses pós-desbaste. Determinou-se densidade básica, poder calorífico superior (PCS) e composição química da madeira, os rendimentos gravimétricos além da densidade aparente, PCS e composição química imediata do carvão vegetal. A madeira apresentou características tecnológicas satisfatórias para produção de carvão vegetal, sob os diferentes níveis de desbaste, porém estes não influenciaram de maneira significativa as propriedades físicas e químicas doccarvão vegetal.

Palavras-chave: Qualidade da madeira; carbonização; práticas silviculturais.
\end{abstract}

\begin{abstract}
Evaluation of different levels of thinning on properties of wood and charcoal from Eucalyptus grandis $x$ Eucalyptus urophylla. This research aimed to evaluate effects of different levels of thinning in the physical and chemical properties of wood and charcoal from a hybrid clone of Eucalyptus urophylla W. Hill ex Maiden x Eucalyptus grandis S. T. Blake. The experiment was conducted in a plot of a forestry company which was divided into four tracks, representing the thinning levels of $0,20,35$ and $50 \%$ applied to five years old plantations. Three trees were collected from each treatment, 62 months after thinning. Basic density, calorific power and chemical composition of wood had been determined, as well as charcoal properties as follows: gravimetric yields, density, chemical immediate composition and calorific power. Wood presented suitable technological characteristics for charcoal production, under different levels of thinning, but these did not influence significantly charcoal physical and chemical properties.
\end{abstract}

Keywords: Wood quality; carbonization; forestry practices.

\section{INTRODUÇÃO}

A diminuição da oferta de combustíveis fósseis, restrições ambientais e aumento do consumo de energia propiciaram o aumento do uso da biomassa como fonte energética, visto que se trata de uma matéria-prima renovável, pouco poluente e de maior disponibilidade no Brasil.

A madeira, e principalmente o carvão vegetal, constituem um dos principais insumos na geração de energia para a matriz energética brasileira.

A qualidade do carvão vegetal é determinada pelas características da matéria-prima utilizada e da tecnologia de conversão. Segundo Campos (2008), no que se refere à matéria-prima, diversas pesquisas envolvendo as propriedades mecânicas, anatômicas, físicas e químicas da madeira vêm sendo realizadas 
com o intuito de promover a seleção de espécies de Eucalyptus destinadas à conversão energética, com vistas à redução da variabilidade das propriedades da madeira, possibilitando aumento do rendimento em carvão vegetal e melhoria das propriedades do carvão necessárias para sua utilização como termorredutor.

As propriedades físicas e químicas do carvão vegetal devem ser consideradas, uma vez que interferem na qualidade do ferro gusa, no qual assume o papel de matéria-prima. Um carvão vegetal com elevado padrão de qualidade para a siderurgia deve apresentar características como elevada densidade aparente, elevado poder calorífico, baixa umidade, baixos teores de materiais voláteis e cinza, além de alto teor de carbono fixo.

A implantação e condução de florestas para a produção comercial de carvão vegetal envolvem a seleção de material genético adequado para tal finalidade e adoção de técnicas silviculturais, aliando a produtividade das florestas à qualidade desejada da madeira para fins energéticos. O uso de madeira mais densa, de maior poder calorífico e com maior porcentagem de lignina em sua composição química contribuem para a maximização do rendimento na produção de carvão vegetal, com maior qualidade (PALUDZYSYN FILHO, 2008).

Como a formação da madeira é um processo biológico, até certo ponto podem-se alterar, controlar, minimizar ou melhorar os fatores relacionados à qualidade da madeira (ZOBEL, 1981). As práticas silviculturais que afetam de forma direta a qualidade da madeira são: espaçamento inicial, fertilização mineral, manutenção, desrama, seleção de material genético e desbastes. De forma simplificada, o desbaste consiste na remoção parcial de árvores em um povoamento, antecipando a mortalidade regular, de modo a concentrar os fatores de crescimento em árvores de características desejáveis ou de maior valor, afetando assim o crescimento das árvores, bem como a qualidade da madeira (SANTOS, 2008).

O desbaste é o tratamento silvicultural mais indicado para produzir árvores de grande porte com qualidade desejável, uma vez que direciona o potencial produtivo de um local para as árvores remanescentes, proporcionando maior crescimento. A retomada do crescimento resulta em aumento significativo do diâmetro das árvores remanescentes, que ingressam em classes de diâmetros superiores (NOGUEIRA, 2003).

A prática do desbaste, além de melhorar a distribuição espacial das árvores, direciona o potencial produtivo do sítio para as árvores de maior valor comercial, evitando que indivíduos indesejáveis ou de menor valor comercial entrem em competição com as árvores desejáveis (SCHULTZ, 1969). O espaço vital de cada árvore é aumentado, proporcionando o desenvolvimento equilibrado da copa e do sistema radicular (SCHNEIDER et al., 1998).

Portanto, esse estudo teve por objetivo avaliar os efeitos dos diferentes níveis de desbaste nas propriedades físicas e químicas da madeira e do carvão vegetal de híbrido de Eucalyptus urophylla W. Hill ex Maiden x Eucalyptus grandis S. T. Blake.

\section{MATERIAL E MÉTODOS}

O experimento foi instalado em um talhão de clone de híbrido de eucalipto (Eucalyptus urophylla W. Hill ex Maiden x Eucalyptus grandis S. T. Blake) de propriedade de uma empresa do setor florestal, no município de Martinho Campos, Minas Gerais. A referida cidade situa-se no noroeste de Minas Gerais, cuja latitude é de $19^{\circ} 34^{\prime} 20^{\prime \prime}$ S, longitude de $45^{\circ} 20^{\prime} 30^{\prime \prime}$ W e altitude de $745 \mathrm{~m}$, apresentando um índice médio pluviométrico anual de $1230,3 \mathrm{~mm}$ e temperatura média anual de $22,1{ }^{\circ} \mathrm{C}$.

O talhão foi dividido em quatro faixas de desbaste, representando os tratamentos estudados, sendo que em cada faixa foram instaladas três parcelas com área em torno de $2.600 \mathrm{~m}^{2}$, totalizando 12 parcelas no talhão.

O experimento foi instalado quando as árvores se encontravam em idade próxima à estagnação do crescimento, aproximadamente 55 meses, cerca de cinco anos, sendo o espaçamento inicial médio entre plantas de $3 \times 3 \mathrm{~m}$. O desbaste foi realizado com a eliminação dos indivíduos com características inferiores, como, por exemplo, árvores bifurcadas, suprimidas e doentes. Os níveis de intensidade de desbaste (tratamentos) aplicados aos talhões foram determinados pela empresa:

- Testemunha ( $0 \%$ de desbaste);

- $\quad 20 \%$ de desbaste em área basal presente;

- $\quad 35 \%$ de desbaste em área basal presente;

- $50 \%$ de desbaste em área basal presente. 
Foram coletadas três árvores dominantes (repetições) de cada tratamento, uma de cada parcela, aos 62 meses pós-desbaste, quando apresentavam 117 meses de idade. Foram retiradas de cada árvore discos de madeira a $0,25,50,75$ e $100 \%$ da altura comercial do tronco, dos quais foram obtidas cunhas opostas que foram utilizadas para a determinação da densidade básica da madeira. Uma parte do restante do disco foi utilizada para a produção do carvão vegetal e outra parte para a produção de serragem, visando às análises da composição química e poder calorífico superior.

Todas as análises foram conduzidas no Laboratório de Painéis e Energia da Madeira do Departamento de Engenharia Florestal da Universidade Federal de Viçosa (UFV), onde foram determinadas as propriedades físicas e químicas da madeira e, após a sua carbonização em mufla, foi realizada a análise do carvão vegetal produzido.

A densidade básica da madeira foi determinada segundo a norma da Associação Brasileira de Normas Técnicas - ABNT NBR 11941 (ABNT, 2003), utilizando-se duas cunhas opostas de cada posição longitudinal do tronco, e a determinação da densidade básica de cada árvore foi feita através da média aritmética das densidades das respectivas cunhas.

O Poder Calorífico Superior (PCS) da madeira a ser carbonizada foi determinado através de bomba calorimétrica adiabática Ika modelo C 200, de acordo com a norma ABNT NBR 8633 (ABNT, 1983).

Para a determinação da composição química da madeira, as amostras foram primeiramente transformadas em serragem em moinho tipo Wiley, conforme a norma da Technical Association of the Pulp and Paper Industry - TAPPI T257 om-92 (1996). As análises foram efetuadas na fração de serragem, classificadas entre peneiras de 40 e 60 mesh (American Society for Testint and Materials ASTM, 1977) e condicionadas a uma umidade relativa de $50{ }^{ \pm} 2 \%$ e temperatura de $23{ }^{ \pm} 1{ }^{\circ} \mathrm{C}$.

Para determinar o teor de extrativos das madeiras analisadas, utilizou-se a norma TAPPI T204 om-88 (1996), com substituição do benzeno por tolueno, sendo a análise realizada em duplicatas. O teor de lignina insolúvel foi determinado pelo método Klason, modificado de acordo com o procedimento proposto por Gomide e Demuner (1986). A lignina solúvel em ácido foi determinada a partir do filtrado resultante da análise da lignina Klason por meio de leitura em espectrofotômetro, de acordo com Goldschimid (1971). O teor de lignina total foi obtido pela soma da lignina insolúvel e solúvel em ácido, enquanto o percentual de holoceluloses foi obtido pelo somatório dos teores de extrativos e lignina totais, decrescido de 100.

Depois de seco em estufa, a uma temperatura de $105 \pm 3{ }^{\circ} \mathrm{C}$, as amostras de madeira na forma de cunha foram colocadas em cadinho metálico com capacidade de aproximadamente $300 \mathrm{~g}$, levado, então, a um forno elétrico (mufla) adaptado, com temperatura inicial igual a $150{ }^{\circ} \mathrm{C}$ e final de $450{ }^{\circ} \mathrm{C}$, sendo o controle do aquecimento feito manualmente, resultando uma taxa de aquecimento de $0,94{ }^{\circ} \mathrm{C} / \mathrm{min}$.

Durante a carbonização, a fração condensável dos gases gerados foi recolhida em um condensador de laboratório adaptado à mufla. Já a fração de gases não condensáveis foi desprezada. Ao final de cada processo de carbonização, o cadinho metálico foi retirado da mufla e submetido a processo de resfriamento natural, para posterior pesagem do carvão e dos produtos condensados. Após cada carbonização, foi determinado o rendimento gravimétrico do carvão em relação à massa seca de madeira, sendo também calculados os rendimentos em gás e em líquidos.

A densidade aparente do carvão foi determinada pela imersão das peças de carvão em mercúrio e sua posterior pesagem, de acordo com Vital (1984).

O PCS do carvão vegetal foi determinado por meio da bomba calorimétrica adiabática Ika modelo C 200, de acordo com a norma ABNT NBR 8633 (1983).

Os procedimentos utilizados para análise química imediata foram realizados de acordo com a norma ABNT NBR 8112 (ABNT, 1983), determinando-se os teores de materiais voláteis, cinzas e carbono fixo, em base seca. As amostras carbonizadas foram preparadas em moinho do tipo Wiley, utilizando-se a fração retida entre as peneiras de 40 e 60 mesh levadas para secagem em estufa a $103{ }^{\circ} \mathrm{C}$.

Para a realização da análise estatística, utilizou-se o delineamento inteiramente casualizado com quatro tratamentos ou níveis de desbastes $(0,20,35$ e 50\%) e três repetições (árvores) por tratamento. O nível de $0 \%$ de desbaste foi considerado como testemunha. Os resultados foram submetidos à análise estatística, utilizando-se o software SAEG 9.1 (2007). Os dados foram submetidos aos testes de Lilliefors, para testar a normalidade, e Cochran, para testar a homogeneidade das variâncias. 
Em seguida os resultados foram submetidos à análise de variância (ANOVA), para verificação das diferenças existentes entre os níveis de desbaste realizados. Quando estabelecidas diferenças significativas entre eles, aplicou-se o teste Tukey em nível de 95\% de significância.

\section{RESULTADOS E DISCUSSÃO}

A tabela 1 mostra os valores médios de densidade básica e PCS da madeira. Os valores médios de densidade básica da madeira não apresentaram diferenças significativas em nível de 5\% de probabilidade de erro e, portanto, os diferentes níveis de desbaste não influenciaram tal propriedade.

Tabela 1. Valores médios de densidade básica da madeira e PCS da madeira, para os diferentes níveis de desbaste.

Table 1. Average values of basic density and wood PCS, for different levels of thinning.

\begin{tabular}{lcc}
\hline $\begin{array}{l}\text { Níveis de desbaste } \\
(\%)\end{array}$ & $\begin{array}{c}\text { Densidade básica } \\
\left(\mathbf{g} / \mathbf{c m}^{3}\right)\end{array}$ & $\begin{array}{c}\text { PCS } \\
(\mathbf{k c a l} / \mathbf{k g})\end{array}$ \\
\hline 0 & 0,593 & $4.767 \mathrm{~b}$ \\
20 & 0,582 & $4.908 \mathrm{a}$ \\
35 & 0,591 & $4.876 \mathrm{ab}$ \\
50 & 0,596 & $4.913 \mathrm{a}$ \\
CV $(\%)$ & 1,70 & 1,67 \\
QMR & 0,000096 & 3860,81 \\
\hline
\end{tabular}

Valores seguidos de mesma letra na vertical não diferem entre si significativamente pelo teste de Tukey (p <0,05); CV: coeficiente de variação (\%); QMR: quadrado médio do resíduo.

A densidade básica da madeira variou de 0,582 a $0,596 \mathrm{~g} / \mathrm{cm}^{3}$, não apresentando diferenças significativas entre os níveis de desbaste aplicados. Os valores encontrados são considerados satisfatórios para a produção de carvão vegetal, uma vez que, quanto maior a densidade da madeira, maior a massa de carvão vegetal produzido para um determinado volume de madeira.

A densidade básica média desse estudo é semelhante a resultados de outros trabalhos, tais como Santos (2010), que, estudando três clones de híbridos de E. urophylla x E. grandis e um híbrido de $E$. camaldulensis x E. grandis, ambos aos sete anos de idade, encontrou valores de densidade básica da madeira de 0,500 a $0,550 \mathrm{~g} / \mathrm{cm}^{3}$, e Oliveira et al. (2010), que analisaram um clone de Eucalyptus pellita aos 5 anos de idade e encontraram valor médio de $0,558 \mathrm{~g} / \mathrm{cm}^{3}$.

Ainda de acordo com a tabela 1, o PCS das madeiras provenientes dos diferentes níveis de desbaste apresentou diferenças significativas entre si. Observa-se menor valor para PCS para a madeira proveniente da testemunha, $4.767 \mathrm{kcal} / \mathrm{kg}$. Os níveis de 20 e $50 \%$ de desbaste apresentaram os maiores valores de poder calorífico, 4.908 e $4.913 \mathrm{kcal} / \mathrm{kg}$, respectivamente. Para o nível de $35 \%$ de desbaste, o valor encontrado para o PCS da madeira foi intermediário, $4.876 \mathrm{kcal} / \mathrm{kg}$, e não diferiu significativamente dos demais tratamentos.

Os valores de PCS deste trabalho são maiores que os encontrados por Quirino et al. (2004), que, em levantamento bibliográfico de dados disponíveis de poder calorífico superior de madeira, encontraram para Eucalyptus urophylla valor médio de $4.588 \mathrm{kcal} / \mathrm{kg}$, enquanto que para Eucalyptus grandis o valor encontrado foi de $4.650 \mathrm{kcal} / \mathrm{kg}$. Santos (2010) também encontrou valores médios para PCS da madeira de Eucalyptus spp. aos sete anos de idade, no município de Carbonita (MG), entre 4.274 e $4.585 \mathrm{kcal} / \mathrm{kg}$, valores estes menores que os encontrados no presente estudo.

O elevado PCS obtido para o nível de $50 \%$ de desbaste foi provavelmente devido a este apresentar maior porcentagem de lignina total e de extrativos em sua composição química, como observado na tabela 2 .

Os teores de extrativos não foram afetados significativamente pelos diferentes tratamentos aplicados, demonstrando que o desbaste não influencia na quantidade de tais componentes químicos. Contudo, verifica-se o maior teor de extrativos na madeira para o nível de 50\% de desbaste, o que pode ter também contribuído para o maior PCS.

A fração de holoceluloses corresponde à soma do teor de celulose e hemiceluloses presentes na madeira. Para os diferentes níveis de desbaste, foram observadas diferenças significativas para o teor de 
holoceluloses, em 5\% de probabilidade de erro. A madeira proveniente da intensidade de 50\% de desbaste apresentou o menor teor de holoceluloses, o que era esperado, uma vez que nesse tratamento foi encontrado o maior teor de lignina, seguida de $35 \%$ de desbaste. Já os maiores teores de holoceluloses foram obtidos para a testemunha e para a madeira de $20 \%$ de desbaste. Esses valores aproximam-se de outros trabalhos que utilizam madeira de eucalipto para fins energéticos, podendo-se destacar Santos (2010), que observou teores de holoceluloses variando de 63,88\% a $65,25 \%$.

Tabela 2. Valores médios da composição química da madeira dos diferentes níveis de desbaste.

Table 2. Average values of wood chemical composition from different levels of thinning.

\begin{tabular}{lccccc}
\hline $\begin{array}{l}\text { Níveis de } \\
\text { desbaste (\%) }\end{array}$ & \multirow{2}{*}{ Extrativos (\%) } & \multirow{2}{*}{ Holoceluloses (\%)* } & \multicolumn{3}{c}{ Lignina (\%)* } \\
\hline 0 & $2,19 \mathrm{a}$ & $66,83 \mathrm{a}$ & $30,98 \mathrm{~b}$ & $27,87 \mathrm{~b}$ & L \\
20 & $1,81 \mathrm{a}$ & $67,00 \mathrm{a}$ & $31,19 \mathrm{~b}$ & $28,36 \mathrm{ab}$ & $2,10 \mathrm{a}$ \\
20 & $2,18 \mathrm{a}$ & $66,56 \mathrm{ab}$ & $31,26 \mathrm{ab}$ & $28,32 \mathrm{ab}$ & $2,94 \mathrm{a}$ \\
35 & $2,29 \mathrm{a}$ & $64,54 \mathrm{~b}$ & $33,17 \mathrm{a}$ & $30,41 \mathrm{a}$ & $2,75 \mathrm{a}$ \\
50 & 15,74 & 4,41 & 7,27 & 1,90 & 3,49 \\
$\mathrm{CV}(\%)$ & 0,101 & 0,706 & 0,504 & 0,757 & 0,035 \\
QMR & &
\end{tabular}

Valores seguidos de mesma letra na vertical não diferem entre si significativamente pelo teste de Tukey ( $\mathrm{p}<0,05)$.

* Valores obtidos a partir de madeira livre de extrativos; CV = coeficiente de variação (\%); QMR = quadrado médio do resíduo.

Quando a finalidade da madeira de eucalipto é a produção de celulose, deseja-se que a ela apresente baixos teores de celulose e hemiceluloses. Isso é devido a tais componentes serem menos resistentes à degradação térmica da madeira, sofrendo uma intensa degradação durante a carbonização e dando origem a uma maior parcela de gases condensáveis e não condensáveis formados, pouco contribuindo para o rendimento gravimétrico em carvão vegetal (FREDERICO, 2009).

As madeiras provenientes de 0 e $20 \%$ de desbaste apresentaram os menores teores de lignina e os maiores teores de holoceluloses. Já para o percentual de 50\% de desbaste, obteve-se o maior valor de lignina total, e, em contrapartida, o menor teor de holoceluloses, evidenciando que esses componentes químicos foram influenciados pela intensidade de desbaste aplicado. De modo geral, observa-se que quanto maior o percentual de desbaste, maior a quantidade de lignina total da madeira. Isso, provavelmente, deve-se a uma maior porcentagem de madeira juvenil no fuste das árvores do tratamento de 50\% de desbaste, uma vez que o espaçamento entre elas também é maior, possibilitando maior crescimento. Zobel e Bujtenen (1989) afirmam que a madeira juvenil apresenta maiores teores de lignina quando comparada à madeira adulta, o que está de acordo com os resultados encontrados.

Visando a produção de carvão, os valores médios encontrados para o teor de lignina são adequados, sendo este o constituinte químico mais importante na produção de carvão, pois tem implicações diretas no rendimento gravimétrico e no teor de carbono fixo. As madeiras com maior teor de lignina possuem maior rendimento gravimétrico em carvão, devido à estrutura complexa da lignina e sua maior resistência à degradação térmica (FREDERICO, 2009).

Por meio das análises físicas e químicas da madeira, foi possível observar que, à medida que se aumentaram os teores de lignina e de extrativos, aumentou proporcionalmente a densidade e o poder calorífico, como verificado para o nível de 50\% de desbaste.

Os valores obtidos para lignina solúvel (Tabela 2) não diferiram estatisticamente entre si. Logo, a diferença encontrada para lignina total das madeiras dos diferentes níveis de desbaste foi devido às diferenças observadas na lignina insolúvel, que constitui a maior proporção do total de lignina presente na madeira. A lignina insolúvel possui uma estrutura mais estável, sendo menos reativa e mais resistente à degradação térmica, podendo contribuir com o aumento do rendimento gravimétrico em carvão vegetal (FREDERICO, 2009).

A testemunha ( $0 \%$ de desbaste) obteve o menor valor de lignina insolúvel $(27,87 \%)$, ocasionando o menor teor de lignina total $(30,98 \%)$ entre todos os tratamentos. O maior valor de lignina insolúvel $(30,41 \%)$ e o maior valor para lignina total $(33,17 \%)$ ocorreram para o nível de $50 \%$ de desbaste. Assim, pode-se constatar que o aumento da intensidade de desbaste proporciona aumento dos teores de lignina insolúvel e consequentemente de lignina total. 
Trugilho et al. (2001) encontraram teores de lignina total de 29,1 a 34,2\% para Eucalyptus grandis, sendo valores correspondentes aos obtidos para os níveis de desbaste estudados no presente trabalho, que tiveram seus teores variando de 30,98 a 33,17\%. Santos (2010) também encontrou teores similares de lignina total para três clones de híbridos de $E$. urophylla $\mathrm{x}$ E. grandis e um híbrido de $E$. camaldulensis x E. grandis, variando de 30,0 a $34,0 \%$.

$\mathrm{Na}$ figura 1 são apresentados os valores em porcentagem (\%) dos rendimentos obtidos durante o processo de carbonização da madeira em mufla.

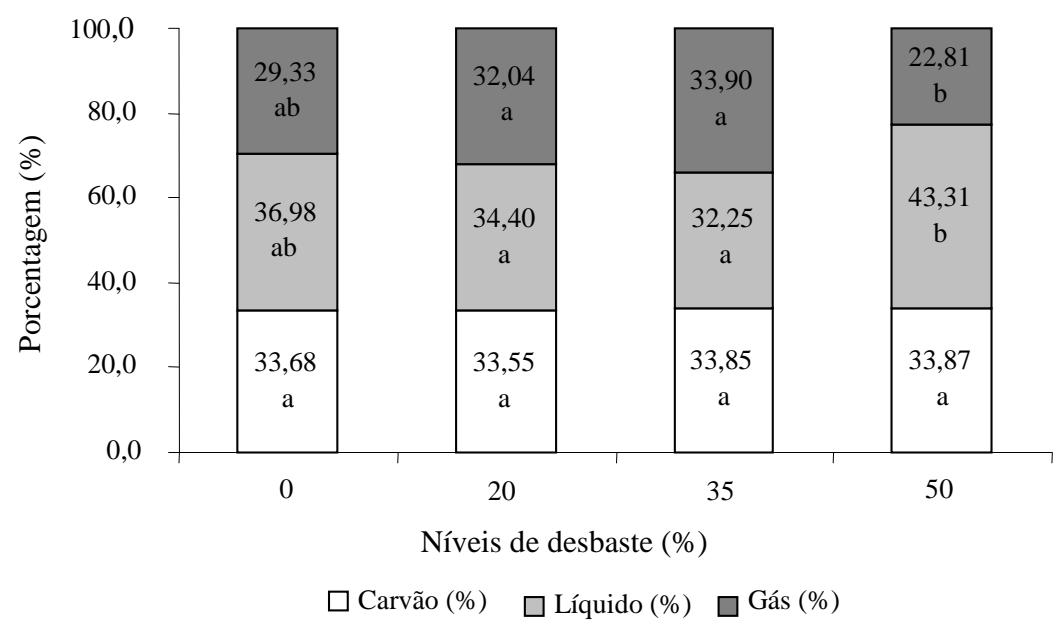

Figura 1. Valores médios em porcentagem dos rendimentos da carbonização para os diferentes níveis de desbaste.

Figure 1. Average values of gravimetric yield carbonization for different levels of thinning.

Valores seguidos de mesma letra não diferem entre si significativamente pelo teste de Tukey $(\mathrm{p}<0,05)$.

O rendimento gravimétrico em carvão vegetal não foi afetado significativamente pelos diferentes níveis de desbaste aplicados no povoamento, com valores médios de 33,55 a 33,87\%. Os valores dos rendimentos gravimétricos em líquido pirolenhoso e em gases não condensáveis foram significativamente afetados pelos tratamentos aplicados. Os tratamentos que apresentaram maior rendimento em líquido apresentaram o menor valor de rendimento de gases.

O maior rendimento de líquido pirolenhoso ocorreu para a carbonização da madeira oriunda de $50 \%$ de desbaste $(43,31 \%)$, seguido pela testemunha (36,98\%). Os níveis de desbaste de 20 e 35\% apresentaram os menores valores de gases condensáveis, não diferindo estatisticamente entre si. $\mathrm{O}$ rendimento em gases não condensáveis apresentou menor valor para o desbaste de $50 \%(22,81 \%)$, que havia apresentado maior rendimento em líquido. Os maiores rendimentos em gases foram observados nos desbastes intermediários ( 20 e $35 \%$ ), que obtiveram rendimento de 32,04 e $33,90 \%$, respectivamente. A testemunha apresentou $29,33 \%$ de rendimento em gases.

Ao determinar a variação de rendimentos gravimétricos da carbonização da madeira de um clone de Eucalyptus urophylla x Eucalyptus grandis aos 6 anos de idade, Arantes (2009) verificou valores médios de 34,37\% de rendimento em carvão vegetal, 47,5\% em gases condensáveis e 17,78\% em gases não condensáveis, em carbonização com temperatura final de $450{ }^{\circ} \mathrm{C}$, tempo de 4 horas, resultando em $1,67^{\circ} \mathrm{C} \cdot \mathrm{min}^{-1}$ de taxa de aquecimento. Os rendimentos em carvão vegetal do trabalho de Arantes (2009) foram semelhantes aos verificados no presente trabalho, enquanto que o rendimento em gases condensáveis foi superiores e o rendimento em gases não condensáveis, inferior. Isso provavelmente é devido à diferença entre as taxas de aquecimento, 1,67 contra $0,94{ }^{\circ} \mathrm{C} \cdot \mathrm{min}^{-1}$, já que maiores taxas de aquecimento resultam na maior proporção de líquidos (gases condensáveis).

$\mathrm{Na}$ tabela 3 são apresentados os resultados obtidos para as análises físicas e químicas realizadas no carvão vegetal produzido a partir da madeira proveniente dos diferentes níveis de desbaste estudados. 
Os maiores valores de densidade aparente (Tabela 3 ) foram observados para a testemunha e para o desbaste de $35 \%$ ( 0,437 e $0,438 \mathrm{~g} / \mathrm{cm}^{3}$, respectivamente). Como a densidade do carvão vegetal está relacionada à madeira de origem, o nível de desbaste de $20 \%$, que apresentou o menor valor de densidade da madeira $\left(0,582 \mathrm{~g} / \mathrm{cm}^{3}\right)$, também apresentou o menor valor de densidade para o carvão. Para fins siderúrgicos, um carvão vegetal de maior densidade é requerido, pois essa propriedade acarreta maior capacidade calorífica por volume, bem como menor volume requerido, além de estar relacionada diretamente com a resistência mecânica do carvão (BOTREL et al., 2007).

Tabela 3. Valores médios de densidade aparente, PCS, materiais voláteis e carbono fixo do carvão vegetal, para os diferentes níveis de desbaste.

Table 3. Average values of charcoal apparent density, caloric power (PCS), volatile matter, ashes and fixed carbon for different levels of thinning.

\begin{tabular}{lccccc}
\hline $\begin{array}{l}\text { Desbaste } \\
(\mathbf{\%})\end{array}$ & $\begin{array}{c}\text { Densidade aparente } \\
\left(\mathbf{g} / \mathbf{c m}^{\mathbf{3}}\right)^{*}\end{array}$ & $\begin{array}{c}\text { PCS } \\
(\mathbf{k c a l} / \mathbf{k g})\end{array}$ & $\begin{array}{c}\text { Materiais voláteis } \\
(\mathbf{\%})\end{array}$ & $\begin{array}{c}\text { Cinzas } \\
(\boldsymbol{\%})\end{array}$ & $\begin{array}{c}\text { Carbono fixo } \\
(\boldsymbol{\%})\end{array}$ \\
\hline 0 & $0,437 \mathrm{a}$ & $7631,6 \mathrm{a}$ & $26,26 \mathrm{a}$ & $0,44 \mathrm{a}$ & $73,30 \mathrm{a}$ \\
20 & $0,390 \mathrm{~b}$ & $7603,8 \mathrm{a}$ & $25,57 \mathrm{a}$ & $0,56 \mathrm{a}$ & $73,86 \mathrm{a}$ \\
35 & $0,438 \mathrm{a}$ & $7632,9 \mathrm{a}$ & $24,46 \mathrm{a}$ & $0,41 \mathrm{a}$ & $75,13 \mathrm{a}$ \\
50 & $0,431 \mathrm{ab}$ & $7559,0 \mathrm{a}$ & $26,43 \mathrm{a}$ & $0,52 \mathrm{a}$ & $73,05 \mathrm{a}$ \\
\hline CV $(\%)$ & 7,22 & 0,73 & 8,64 & 30,48 & 2,99 \\
QMR & 0,000697 & 2894,23 & 5,88 & 0,024073 & 5,73 \\
\hline VMR & & & &
\end{tabular}

Valores seguidos de mesma letra na vertical não diferem entre si significativamente pelo teste de Tukey (p <0,05); CV: coeficiente de variação (\%); QMR: quadrado médio do resíduo; * Umidade: 5\%, em média.

Frederico (2009), trabalhando com diferentes clones de E. grandis x E. urophylla, encontrou valores de densidade do carvão variando de 0,285 a $0,323 \mathrm{~g} / \mathrm{cm}^{3}$, valores inferiores aos obtidos neste trabalho. As diferenças entre a densidade aparente dos carvões podem ser explicadas pela menor densidade básica da madeira dos clones estudados pelo autor. Em estudo feito por Trugilho et al. (2001), foram observados valores para essa variável em clones de Eucalyptus grandis variando entre 0,399 e $0,486 \mathrm{~g} / \mathrm{cm}^{3}$, valores próximos aos verificados nesse trabalho.

Ainda de acordo com a tabela 3, ao nível de 5\% de probabilidade, não foram observadas diferenças significativas no PCS do carvão vegetal para as diferentes intensidades de desbaste realizadas. Normalmente, o poder calorífico do carvão vegetal varia de 6.400 a $7.500 \mathrm{kcal} / \mathrm{kg}$ (LÚCIO, 2008), dependendo da madeira e forma de carbonização. Pereira et al. (2000), ao estudarem as características da madeira de cinco espécies de eucalipto, com dez anos e meio, encontraram valores para o PCS entre 6.626 e $8.088 \mathrm{kcal} / \mathrm{kg}$. Portanto, observa-se na tabela 3 que os carvões produzidos com a madeira proveniente dos diferentes desbastes apresentam PCS condizentes com o que normalmente é verificado na literatura.

O poder calorífico do carvão é resultado da combinação entre o teor de carbono fixo e do teor de materiais voláteis. Quanto maior o teor de carbono fixo no carvão vegetal, maior seu PCS, e este, por sua vez, é inversamente proporcional ao teor de cinzas e ao teor de materiais voláteis. Logo, o maior valor de PCS $(7.632 \mathrm{kcal} / \mathrm{kg})$ foi encontrado para o nível de $35 \%$ de desbaste, que apresentou o maior teor de carbono fixo e menores teores de cinzas e materiais voláteis, como observado na tabela 3.

De acordo com a análise de variância, não houve efeito dos diferentes níveis de desbaste na análise química do carvão vegetal (Tabela 3). Observa-se que teor de materiais voláteis dos carvões variou de 24 a $26 \%$. Para uso siderúrgico, valores menores que $25 \%$ de materiais voláteis no carvão são desejados (SANTOS, 2008). Assim, somente o carvão vegetal produzido com madeira de $35 \%$ de desbaste atende essa exigência $(24,46 \%)$. As intensidades de 0,20 e $35 \%$ de desbaste obtiveram, de acordo com a tabela 3 , valores superiores a $25 \%$ de materiais voláteis.

$\mathrm{O}$ teor de materiais voláteis representa os compostos remanescentes da degradação da madeira e do alcatrão, que não se desprenderam durante o processo de carbonização, permanecendo assim como componentes químicos do carvão (CORRÊA, 1988). Uma fração de voláteis é necessária no carvão, devido ao aumento da permeabilidade da carga no alto forno e à diminuição da reatividade do carvão vegetal. Para uso doméstico, um alto teor de voláteis ocasiona o desconforto da fumaça, além de menor eficiência energética, acarretando maior consumo de carvão vegetal (FREDERICO, 2009). 
As cinzas são provenientes do conteúdo mineral do lenho e, principalmente, da casca da madeira a ser carbonizada (VITAL et al., 1986). Seu valor deve ser inferior a 1\%, resultado encontrado para todos os tratamentos analisados, o que demonstra não ter havido contaminação da madeira nem do carvão vegetal.

As porcentagens de 20 e $50 \%$ de desbaste apresentaram os maiores valores de cinzas $(0,560 \mathrm{e}$ $0,524 \%)$, enquanto que a testemunha $(0 \%)$ e $35 \%$ de desbaste apresentaram os menores teores, 0,440 e $0,407 \%$, respectivamente.

Para o teor de carbono fixo também não foi verificada a existência de diferença significativa ao nível de 5\% de significância entre os diferentes níveis de desbaste. Os valores de carbono fixo encontrados neste trabalho foram superiores aos obtidos por Barcellos (2007), que, determinando o teor de carbono fixo de diferentes espécies de Eucalyptus, obteve valores variando de 69,31\% para E. urophylla a $72,79 \%$ para E. camaldulensis.

Normalmente, quanto maior o teor de carbono fixo, menor é o teor de materiais voláteis. Isso pode ser observado na tabela 3: o maior teor de carbono fixo $(75,13 \%)$ foi obtido pelo nível de $35 \%$ de desbaste, que apresentou também o menor teor de materiais voláteis $(24,46 \%)$. Os demais tratamentos tiveram comportamento inverso, apresentando menor teor de carbono fixo e maior teor de materiais voláteis.

\section{CONCLUSÕES}

- A madeira do clone de Eucalyptus urophylla x Eucalyptus grandis avaliado apresentou características tecnológicas satisfatórias para produção de carvão vegetal, sob diferentes níveis de desbaste.

- Em geral, as propriedades da madeira referentes ao nível de 50\% de desbaste apresentaram os melhores resultados para a produção de carvão vegetal.

- Os diferentes níveis de desbaste não influenciaram de maneira significativa as propriedades físicas e químicas carvão vegetal.

- Sugere-se que seja feita a análise econômica do projeto para se verificar a viabilidade do desbaste para a produção de carvão vegetal, além da análise da produtividade em cada nível de desbaste.

\section{REFERÊNCIAS}

AMERICAN SOCIETY FOR TESTING AND MATERIALS (ASTM). Standard method for chemical analyses of wood charcoal. Phyladelphia: 1977. $1042 \mathrm{p}$.

ARANTES, M. D. C. Variação nas características da madeira e do carvão vegetal de um clone de Eucalyptus grandis W. Hill ex Maiden $\mathbf{x}$ Eucalyptus urophylla S.T. Blake. 2009. 149 f. Tese (Doutorado em Ciência e Tecnologia da Madeira) - Universidade Federal de Lavras, Lavras, MG, 2009.

ASSOCIAÇÃO BRASILEIRA DE NORMAS TÉCNICAS (ABNT). Normas técnicas NBR 8112. Brasília, 1983. n. p.

. Normas técnicas NBR 8633. Brasília, 1983. n. p.

Normas técnicas NBR 11941. Brasília, 2003. 6 p.

BARCELLOS, D. C. Caracterização do carvão vegetal através do uso de espectroscopia no infravermelho próximo. $140 \mathrm{f}$. Tese (Doutorado em Ciência Florestal) - Universidade Federal de Viçosa, Viçosa, MG, 2007.

BOTREL, M. C. G.; TRUGILHO, P. F.; ROSADO, S. C. S.; SILVA, J. R. M. da. Melhoramento genético das propriedades do carvão vegetal de Eucalyptus. Revista Árvore, 2007, v. 31, n. 3, p. 391 - 398.

CAMPOS, A. C. M. Carvão de Eucalyptus: efeito dos parâmetros da pirólise sobre a madeira e seus componentes químicos e predição da qualidade pela espectroscopia NIR. 2008. 118 p. Dissertação (Mestrado em Ciência e Tecnologia da Madeira) - Universidade Federal de Lavras, Lavras, MG. 2008. 
CORRÊA, A. A. Conversão química de madeiras da Amazônia: carvão e briquetes de carvão vegetal. Acta Amazônica, Manaus, AM, v. 18, n. 1, p. 93 - 108, 1988.

FREDERICO, P. G. U. Influência da densidade e composição química da madeira sobre a qualidade do carvão de Eucalyptus grandis W. Hill ex Maiden e de híbridos de Eucalyptus grandis $\mathbf{x}$ Eucalyptus urophylla S.T. Blake. 75 f. Dissertação (Mestrado em Ciência Florestal) - Universidade Federal de Viçosa, Viçosa, MG, 2009.

GOLDSCHIMID, O. Ultraviolet spectra. In: SARKANEN, K. V.; LUDWING, C. H. (eds.). Lignins. New York: Wiley Interscience, 1971. p. 241 - 266.

GOMIDE, J. L.; DEMUNER, B. J. Determinação do teor de lignina em material lenhoso: método Klason modificado. O Papel, v. 47, n. 8, p. 36 - 38. 1986.

LÚCIO, A. Tecnologia DPC para produção de carvão vegetal. In: Fórum nacional de carvão vegetal, 2008, Belo Horizonte. Disponível em: <painelfloresta+l.com.br/exibeNews.php?id=1784>. Acesso em: $31 / 05 / 2009$.

NOGUEIRA, G. S. Modelagem do crescimento e da produção de povoamentos de Eucalyptus sp. e de Tectona grandis submetidos a desbaste. 132 f. Tese (Doutorado em Ciência Florestal) - Universidade Federal de Viçosa, Viçosa, MG, 2003.

OLIVEIRA, A. C.; CARNEIRO, A. C. O.; VITL, B. R.; ALMEIDA, W.; PEREIRA, B. L. C.; CARDOSO, M. T. Parâmetros de qualidade da madeira e do carvão vegetal de Eucalyptus pellita $\mathrm{F}$. Muell. Revista Scientia Forestalis, Piracicaba, São Paulo v. 38, n. 87, p. 431 - 439, 2010.

PALUDZYSYN FILHO, E. Melhoramento do eucalipto para a produção de energia. Revista Opiniões, Ribeirão Preto, jun.-ago. 2008. Disponível em: <www.revistaopinioes.com.br/cp/edicao_materias.php? id=15>. Acesso em: 31/05/2009.

PEREIRA, J. C. D.; SCHAITZA, E. G.; BAGGIO, A. J. Propriedades físicas e químicas e rendimentos da destilação seca da madeira de Grevillea robusta. Colombo: Embrapa Florestas, 2000. (Embrapa Florestas. Circular técnica, 40).

QUIRINO, W. F.; VALE, A. T.; ANDRADE, A. P. A.; ABREU, V. L. S.; AZEVEDO, A. C. dos S. Poder calorífico da madeira e de materiais ligno-celulósicos. Biomassa \& Energia, v. 1, n. 2, p. 173 - 182, 2004.

SANTOS, F. L. Regulação da produção de floresta de eucalipto submetida a desbaste e destinada a multiprodutos. 80 f. Dissertação (Mestrado em Ciência Florestal) - Universidade Federal de Viçosa, Viçosa, 2008.

SANTOS, R. C. Parâmetros de qualidade da madeira e do carvão vegetal de clones de eucalipto. 173 f. Tese (Doutorado em Ciência e Tecnologia da Madeira) - Universidade Federal de Lavras, Lavras, 2010.

SCHULTZ, J. P. Curso de Silvicultura I. Merida: Universidade de Los Andes, Centro de Estudios de Posgrado, 1969. 29 p.

SCHNEIDER, P. C.; FINGER, C. A. G.; HOPPE, J. M.; DRESCHER, R.; SCHEEREN, L.; MAINARDI, G.; FLEIG, F. D. Produção de Eucalyptus grandis Hill ex Maiden em diferentes intensidades de desbaste. Ciência Florestal, Santa Maria, v. 8, n. 1, p. 129 - 140, 1998.

TRUGILHO, P. F.; LIMA, J. T.; MORI, F. A.; LINO, A. L. Avaliação de clones de Eucalyptus para produção de carvão vegetal. Cerne, Lavras, v. 7, n. 2, p. 104 - 114, 2001.

TECHNICAL ASSOCIATION OF THE PULP AND PAPER INDUSTRY (TAPPI). TAPPI test methods T 204 om-88: solvent extractives of wood and pulp. Atlanta: Tappi Technology Park, 1996. v. 1.

. TAPPI test methods T $264 \mathrm{om}-88$ : preparation of wood for chemical analysis. Atlanta: Tappi Technology Park, 1996. v. 1.

TAPPI test methods T $257 \mathrm{~cm}-85$ : sampling and preparing wood for anelysis. Atlanta: Tappi Technology Park, 1996. v. 1. 
VITAL, B. R. Métodos de determinação da densidade da madeira. Viçosa, SIF, 21 p. (Boletim Técnico I). 1984.

VITAL, B. R.; JESUS, R. M.; VALENTE, O. F. Efeito da constituição química e da densidade da madeira de clones de Eucalyptus grandis na produção de carvão vegetal. Revista Árvore, Viçosa, v. 10, n. 2, p. $151-160,1986$.

ZOBEL, B. Wood quality from fast-grown plantation. In: TAPPI, the Journal of the Technical Association of the Pulp and Paper Industry. v. 64, n. 1, January, 1981.

ZOBEL, J. B.; BUJTENEN, J. P. Wood variation: its causes and control. New York: Springer-Verlag, 1989. $363 \mathrm{p}$. 